DOI 10. 18307/2017. 0313

(C) 2017 by Journal of Lake Sciences

\title{
松花江哈尔滨段浮游动物群落结构特征与水质评价
}

\author{
鞠永富 ${ }^{1,2}$, 于洪贤 ${ }^{1 * *}$, 于 婷 ${ }^{2}$, 柴方营 ${ }^{2}$,姚允龙 ${ }^{1}$, 于 鹏 $^{1}$ \\ (1: 东北林业大学, 哈尔滨 150040$)$ \\ (2: 黑龙江省水利厅, 哈尔滨 150001$)$
}

\begin{abstract}
摘 要: 2012 年对松花江哈尔滨段浮游动物群落结构进行调查研究, 并结合理化指标评价法对水质进行评价. 结果显 示: 共鉴定出浮游动物 40 种, 其中原生动物 9 种, 轮虫 27 种, 枝角类 2 种, 桡足类 2 种; 污染指示种 34 种, 其中塞污性为 10 种, $0-\beta$ 中污性为 6 种, $\beta$-中污性为 9 种, $\beta-\alpha$ 中污性为 4 种, $\alpha$-中污性为 5 种; 全年平均丰度为 $1042.0 \mathrm{ind}$. $/ \mathrm{L}$, 生物量为 $0.078 \mathrm{mg} / \mathrm{L}$. 常见种有颌花臂尾轮虫 (Brachionus quadridentatus) 、螺形龟甲轮虫 (Keratella cochlearis) 和针簇多肢轮虫 (Polyarthra trigla), 均为中污染指示种; 各样点污染程度在季节变化和全年变化中均表现一致, 总体是上游水质优于下游, 季 节污染程度是夏季>秋季>春季. 整体评价结果显示, 松花江哈尔滨段水体已处于中富营养水平、中度污染状态. 本研究结 果可为松花江水质生态评价、水环境监测及水资源管理提供重要的理论依据.
\end{abstract}

关键词: 松花江哈尔滨段;浮游动物; 群落结构;水质评价

\section{Zooplankton community structure characters and water quality assessment in Harbin sec- tion of Songhua River}

\author{
JU Yongfu $^{1,2}$, YU Hongxian ${ }^{1 * *}$, YU Ting ${ }^{2}$, CHAI Fangying ${ }^{2}$, YAO Yunlong ${ }^{1} \&$ YU Peng ${ }^{1}$ \\ (1: Northeast Forestry University, Harbin 150040, P.R. China) \\ (2: Department of Water Resources of Heilongjiang Province, Harbin 150001, P.R.China)
}

\begin{abstract}
In 2012, the zooplankton community structure in Harbin section of Songhua River was surveyed, and chemical index evaluation methods were used to assess the condition of water quality. A total of 40 species of zooplankton were found, including 9 species of protozoa, 27 species of Rotifera, 2 species of Cladocera, and 2 species of Copepoda. There are 34 species which could be treated as polluted indicators, in which 10 species are in light level, 6 species are in o- $\beta$ in middle level, 9 species are in $\beta$ middle level, 4 species are in $\beta-\alpha$ middle level, and 5 species are in $\alpha$ middle level. The annual average richness is 1042.0 ind./L, and the biomass is $0.078 \mathrm{mg} / \mathrm{L}$. The common species are Brachionus quadridentatus, Keratella cochlearis and Polyarthra trigla, which are all mesosaprobity pollution indicators. The pollution degree of all kinds at the sample sites is consistent with the seasonal variation and the annual variation, where the water quality of the upstream is better than that of the downstream. The ordination of seasonal pollution degree from strong to weak levels is summer $>$ autumn $>$ spring. Overall evaluation results showed that, Harbin section of the Songhua River has been polluted in middle eutrophication level and in moderately polluted state. This study reflects that the current status of water quality objectively provides the important scientific basis for the Songhua River water quality and ecological assessment, water environment monitoring and water resources management.
\end{abstract}

Keywords: Harbin section of Songhua River; zooplankton; community structure; water quality assessment

水生态指标评价法是指利用水生生物的指示作用评价水体污染的一种生态学评价法, 与理化评价法相 比, 具有投人少、监测频次低、连续性好等特点, 是对环境质量状况的真实评价, 也是水环境质量评价的发展 趋势, 对水生态的恢复具有十分重要的意义. 浮游动物作为指示生物能够反映水体水质状况 ${ }^{[1-3]}$, 其群落结

* 黑龙江省科技攻关项目 (GB09C103) 资助. 2015-10-08 收稿; 2016-07-25 收修改稿. 鞠永富 (1984 ), 男, 博 士研究生; E-mail : juyongfu@ 163.com.

** 通信作者; E-mail: china.yhx@163.com. 
构与水体富营养化程度密切相关 ${ }^{[4-5]}$. 松花江发源于吉林省长白山天池, 其哈尔滨段上游始于三家子,下游 止于大顶子山, 有阿什河、呼兰河两个一级支流. 2005 年松花江水污染事件暴发后, 对其研究逐渐增多. 孟伯

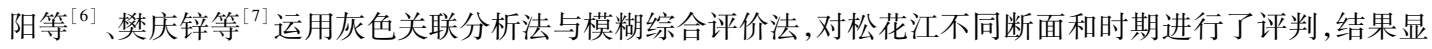
示不同水期对水环境质量有关联影响, 不同断面水环境质量的差异则主要取决于支流污染源汇人以及水体 稀释、降解自净作用; 宫凯悦 ${ }^{[8]}$ 从底泥重金属含量、多元统计分析和污染程度及风险评价 3 个方面,综合分 析了松花江哈尔滨段沉积物的重金属污染特性,结果表明松花江哈尔滨段各重金属含量除临近何家沟排污 口采样点外, 沿上游到下游呈逐渐升高的趋势. 各重金属之间浓度比较结果为 $\mathrm{Zn}>\mathrm{Cr}>\mathrm{Pb}>\mathrm{Cu}>\mathrm{Ni}>\mathrm{Cd}$; 李静 文 $^{[9]}$ 、孙洋阳等 ${ }^{[10]}$ 对松花江哈尔滨段的研究表明, 温度升高、溶解氧不足、氧化还原电位过低及剧烈扰动会 促进底泥中有机质及氨氮的释放, 而温度升高、 $\mathrm{pH}$ 的降低都会抑制底泥对氨氮的吸附. 已有研究均以理化 指标研究为主, 本文通过对松花江哈尔滨段浮游动物进行调查研究, 运用生态学分析法, 并结合理化指标评 价法对其水质进行评价, 以期为松花江哈尔滨段水质生态评价和水环境监测提供科学依据.

\section{1 材料和方法}

\section{1 采样时间和地点}

于 2012 年春季 ( 5 月)、夏季 ( 7 月) 和秋季 (10 月), 根据松花江哈尔滨段各样点所具有的代表性, 共设 置 9 个断面 (用 $\mathrm{S} 1 \sim \mathrm{S} 9$ 表示) (图 1), 每个断面设两个样点, 即断面的右岸 (或者左岸) 和中间.

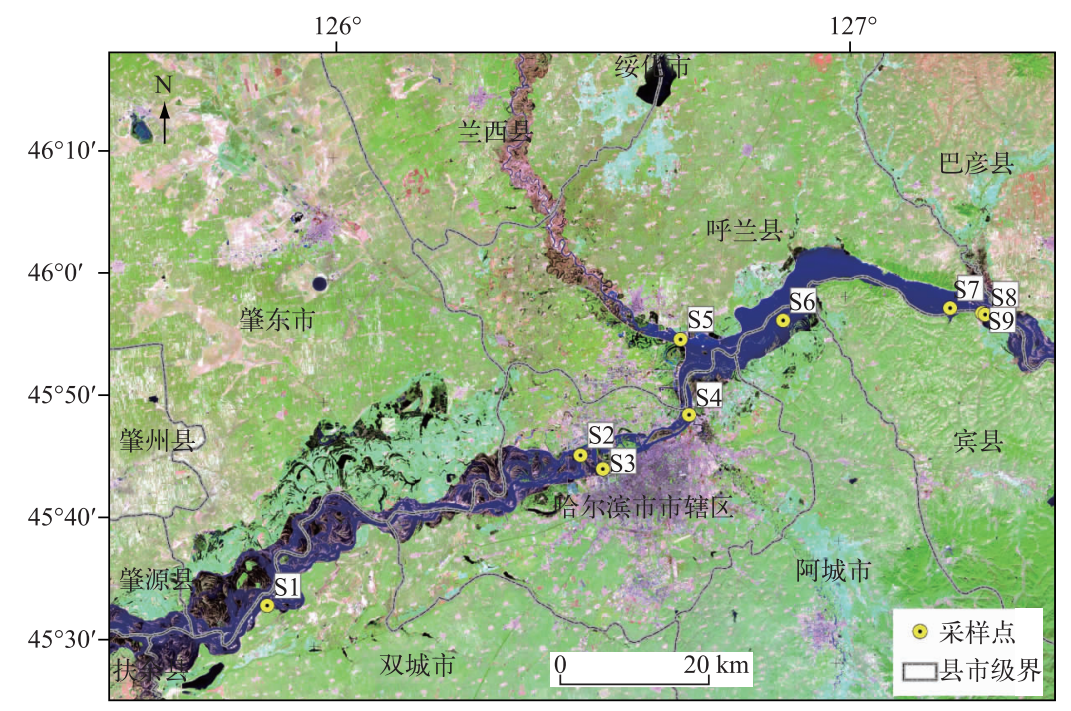

图 1 松花江哈尔滨段样点分布 (S1 为三家子, $\mathrm{S} 2$ 为金河湾湿地公园, $\mathrm{S} 3$ 为二水源, $\mathrm{S} 4$ 为水泥厂, $\mathrm{S} 5$ 为呼兰河口, $\mathrm{S} 6$ 为大亮子, $\mathrm{S} 7$ 为卜家口屯, $\mathrm{S} 8$ 为大顶子山黄鱼圈, $\mathrm{S} 9$ 为大顶子山黄鱼圈下)

Fig.1 Distribution of sampling sites in Harbin section of Songhua River

\section{2 样品采集与数据处理}

样品的采集、鉴定及丰度和生物量的计算等均参照《淡水浮游生物调查技术规范》 ${ }^{[11]}$. 现场采集水样带 回实验室, 参照《湖泊富营养化调查规范》 ${ }^{[12]}$ 进行溶解氧 $(\mathrm{DO})$ 、高锰酸盐指数 $\left(\mathrm{COD}_{\mathrm{Mn}}\right)$ 、五日生化需氧量 $\left(\mathrm{BOD}_{5}\right)$ 、氨氮 $\left(\mathrm{NH}_{3}-\mathrm{N}\right)$ 、总氮 $(\mathrm{TN})$ 和总磷 $(\mathrm{TP})$ 浓度测定分析, 其中 $\mathrm{DO}$ 浓度用叠氮化钠改良法测定, $\mathrm{COD}_{\mathrm{Mn}}$ 用高镇酸盐指数法测定, $\mathrm{BOD}_{5}$ 用稀释接种法测定, $\mathrm{NH}_{3}-\mathrm{N}$ 浓度用纳氏试剂法测定, $\mathrm{TN}$ 浓度用过硫酸 钾氧化-紫外分光光度法测定, TP 浓度用过硫酸钾消解一钿锑抗分光光度法测定.

水生态学评价方法包括现存量法和常见种指示生物法 ${ }^{[13-14]}$. 浮游动物现存量主要是指丰度和生物量, 丰度 $<1000$ ind. $/ \mathrm{L}$ 为贫营养, $1000 ~ 3000$ ind. $/ \mathrm{L}$ 为中营养, $>3000$ ind. $/ \mathrm{L}$ 为富营养; 生物量 $<1 \mathrm{mg} / \mathrm{L}$ 为贫营 养, $1 \sim 3 \mathrm{mg} / \mathrm{L}$ 为中营养, $>3 \mathrm{mg} / \mathrm{L}$ 为富营养. 有研究指出, 污染系统和河流不同污染带的指示生物种类都对 
环境有特殊的要求, 只有当水体中存在这些环境条件的前提下, 这种指示生物种类才能生存 ${ }^{[15]}$, 因此可用对 水质具有指示作用的生物来监测和评价水体的污染状况.

水质理化指标评价包括单因素评价法 ${ }^{[16]}$ 和综合污染指数法 ${ }^{[17]}$. 单因素评价法是以 $\mathrm{DO} 、 \mathrm{COD}_{\mathrm{Mn}} 、 \mathrm{BOD}_{5}$ 、 $\mathrm{NH}_{3}-\mathrm{N}$ 、TN 和 TP 6 个指标作为单因素评价因子, 参照《地表水环境质量标准》( GB 3838-2002) 评价各样点 各季节水质.

综合污染指数评价法表达式为:

$$
\begin{gathered}
P=1 / n \sum P_{i} \\
P_{i}=C_{i} / C o_{i}
\end{gathered}
$$

式中, $P$ 为综合污染指数, $P_{i}$ 为污染物单项污染指数, $C_{i}$ 为污染物监测值 $(\mathrm{mg} / \mathrm{L}), C o_{i}$ 为污染物标准值

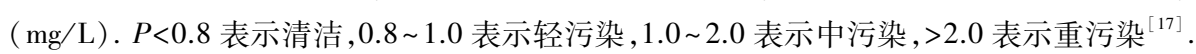

\section{2 结果与分析}

\section{1 群落结构和水质生态学评价}

本次调查共鉴定出浮游动物 40 种, 其中原生动物 9 属 9 种, 占 $22.5 \%$; 轮虫 15 属 27 种, 占 $67.5 \%$; 枝角 类 2 属 2 种, 占 $5.0 \%$; 桡足类 2 属 2 种, 占 $5.0 \%$. 各样点中,种类数量最多的是 $\mathrm{S} 4$ 右样点 $(21$ 种), 占 $8.36 \%$, 其次是 S6 右样点 (18 种), 占 7.17\%, 最少的是 S3 右样点 (9 种), 占 3.58\%. 污染指示种 34 种 (表 1 ), 其中寡 污性种类 10 种, 占 $29.41 \% ; 0-\beta$ 中污性种类 6 种, 占 $17.65 \%$; $\beta$-中污性种类 9 种, 占 $26.47 \%$; $\beta-\alpha$ 中污性种类 4 种, 占 $11.76 \% ; \alpha$-中污性种类 5 种, 占 $14.71 \%$. 中污性种类较多, 可见松花江哈尔滨段水体已处于中度 污染.

春季常见种包括萼花臂尾轮虫、螺形龟甲轮虫、长三肢轮虫和小剑水蚤 (Microcyclops), 均是富营养和中 度富营养指示种; 夏季常见种包括螺形龟甲轮虫和针簇多肢轮虫, 是中度富营养指示种; 秋季常见种包括小 口钟虫、绿急游虫、萼花臂尾轮虫、螺形龟甲轮虫和针簇多肢轮虫, 除绿急游虫外, 其余均为中度富营养指 示种.

按丰度指标评价,松花江哈尔滨段春季 $\mathrm{S} 1$ 右、S2 右、S4 右、S6 右、S8 左和 S9 右采样点, 夏季 S1 右采样 点, 秋季 $\mathrm{S} 1$ 右、S2 中、S6 中和 $\mathrm{S} 8$ 左采样点为中营养状态, 秋季 $\mathrm{S} 1$ 中、S2 右、S3 中、S3 右和 $\mathrm{S} 4$ 中和 $\mathrm{S} 8$ 中采 样点为富营养状态, 其余各点均为贫营养状态; 按生物量指标评价, 3 个季节中松花江哈尔滨段各样点均为 贫营养状态. 浮游动物春季、夏季和秋季丰度分别为 903.9、215.4 和 2006.7 ind./L, 生物量分别为 0.121 、 0.029 和 $0.084 \mathrm{mg} / \mathrm{L}$. 按丰度指标评价, 松花江哈尔滨段水体污染程度最严重的是秋季, 为中营养状态, 其次 是春季和夏季, 都为贫营养状态; 按生物量指标评价 3 个季节污染程度都为贫营养状态. 浮游动物全年平均 丰度为 1042.0 ind./L,生物量为 $0.078 \mathrm{mg} / \mathrm{L}$, 按丰度指标评价, 水体已达到中营养状态; 按生物量指标评价, 水体没有达到中营养状态 (图 2).

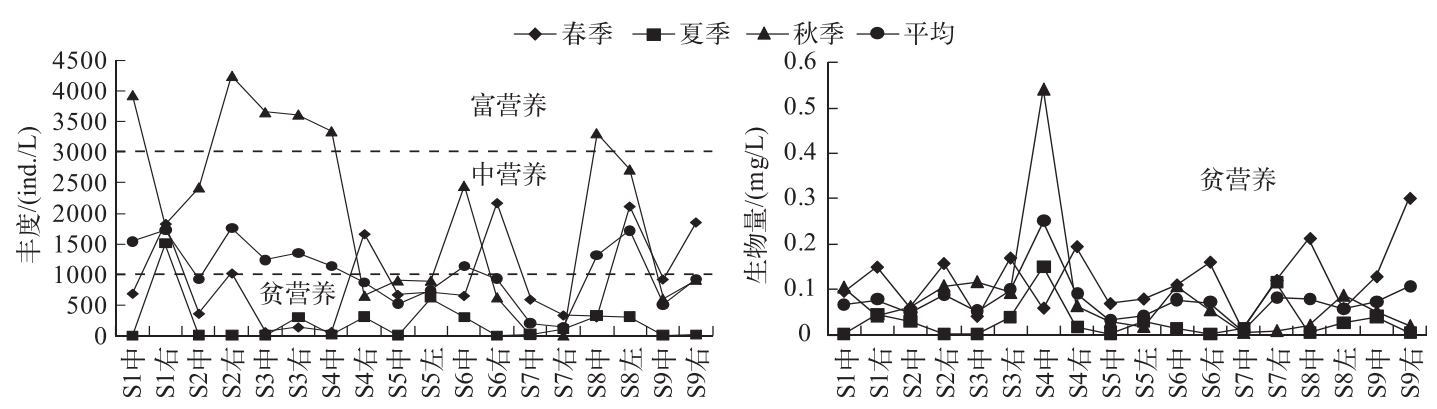

图 2 松花江哈尔滨段浮游动物丰度和生物量

Fig. 2 The zooplankton abundance and biomass in Harbin section of Songhua River 
表 1 浮游动物污染指示等级及出现频率 ${ }^{*}$

Tab.1 Zooplankton indicating pollution level and occurrence frequency

\begin{tabular}{|c|c|c|c|c|}
\hline 浮游动物 & 种类 & 拉丁名 & 污染等级 & 频率 \\
\hline \multirow[t]{7}{*}{ 原生动物 } & 小口钟虫 & Vorticella microstoma & $\alpha$ & ++ \\
\hline & 王氏似铃壳虫 & Tintinnopsis wangi & o & ++ \\
\hline & 陀螺侠盗虫 & Strobilidium velox & o & + \\
\hline & 瓶累枝虫 & Epistylis urceolata & $\alpha$ & + \\
\hline & 绿急游虫 & Strombidum viride & o & ++ \\
\hline & 大口表壳虫 & Arcella megastoma & $\alpha$ & + \\
\hline & 尖顶砂壳虫 & Difflugia acuminata & o & + \\
\hline \multirow[t]{27}{*}{ 轮虫 } & 角突臂尾轮虫 & Brachionus angularis & $\beta-\alpha$ & + \\
\hline & 壸状臂尾轮虫 & Brachionus urceus & $\beta-\alpha$ & + \\
\hline & 䔅花臂尾轮虫 & Brachionus quadridentatus & $\beta-\alpha$ & +++ \\
\hline & 裂足臂尾轮虫 & Brachionus diversicornis & $\beta$ & + \\
\hline & 螺形龟甲轮虫 & Keratella cochlearis & $\beta$ & +++ \\
\hline & 矩形龟甲轮虫 & Keratella quadrata & $\beta$ & + \\
\hline & 曲腿龟甲轮虫 & Keratella valga & $o-\beta$ & + \\
\hline & 针簇多肢轮虫 & Polyarthra trigla & $\beta-\alpha$ & +++ \\
\hline & 真翅多肢轮虫 & polyarthra euryptera & $\alpha$ & + \\
\hline & 长刺盖氏轮虫 & Kellicottica longispina & $0-\beta$ & + \\
\hline & 长三肢轮虫 & Filinia longiseta & $\alpha$ & ++ \\
\hline & 迈氏三肢轮虫 & Filinia maior & $\beta$ & + \\
\hline & 尖尾疮毛轮虫 & Synchaeta stylata & o & + \\
\hline & 长圆疮毛轮虫 & Synchaeta pectinata & $\beta$ & + \\
\hline & 罗氏腔轮虫 & Lecane ludwigii & o & + \\
\hline & 共趾腔轮虫 & Lecane sympoda & 0 & + \\
\hline & 月形腔轮虫 & Lecane luna & $0-\beta$ & + \\
\hline & 前节晶囊轮虫 & Asplanchna priodonta & $\beta$ & + \\
\hline & 郝氏㱀甲轮虫 & Ploesoma hudsoni & $0-\beta$ & + \\
\hline & 扁平泡轮虫 & Pompholyx complanata & $\beta$ & + \\
\hline & 特异同尾轮虫 & Diurella insignis & $\beta$ & + \\
\hline & 圆筒异尾轮虫 & Trichocerca cylindrica & $0-\beta$ & + \\
\hline & 冠饰异尾轮虫 & Trichocerca lophoessa & o & + \\
\hline & 纵长异尾轮虫 & Trichocerca elongata & o & + \\
\hline & 腹足腹尾轮虫 & Gastropus hyptopus & o & + \\
\hline & 方块鬼轮虫 & Trichotria tetractic & $0-\beta$ & + \\
\hline & 四齿单趾甲轮虫 & Monostyla quadridentata & $\beta$ & + \\
\hline
\end{tabular}

* 出现频率低于 $25 \%$ 为,$+ 25 \% \sim 50 \%$ 为 ++ , 高于 $50 \%$ 为 $+++; 0$ : 塞污; $0-\beta: 0$-塞污 $-\beta$ 中污; $\beta: \beta-$ 中污; $\beta-\alpha: \beta-\alpha$ 中污; $\alpha: \alpha-$ 中污.

\section{2 水质理化指标评价}

2.2.1 水质理化单因素指标评价 根据水质理化指标数据, 对照《地表水环境质量标准》(GB 3838-2002) 可 以看出, 松花江哈尔滨段各样点污染程度在季节变化和全年变化中均表现一致(图 3 ), 总体为上游水质优于 下游. 春季优于 III 类水质标准 (包括 III 类) 的共 25 个样本, 劣于 III 类水质的共 11 个样本, 分别占春季总数的 $69.44 \%$ 和 $30.56 \%$; 夏季优于 III类水质标准 (包括 III 类) 的共 24 个样本, 劣于 III 类水质的共 12 个样本, 分别 占 $66.67 \%$ 和 $33.33 \%$; 秋季优于 III类水质标准 (包括 III 类) 的共 32 个样本, 劣于III类水质标准的共 4 个样本, 分别占 $88.89 \%$ 和 $11.11 \%$. 各季节污染程度排序为夏季 $>$ 春季 $>$ 秋季. 松花江哈尔滨段 3 个季节优于 III类水质 标准 (包括 III类) 的共计 81 个样本, 占总量的 $75 \%$. 可见,松花江哈尔滨段全年水质较好, 满足 III类水标准. 

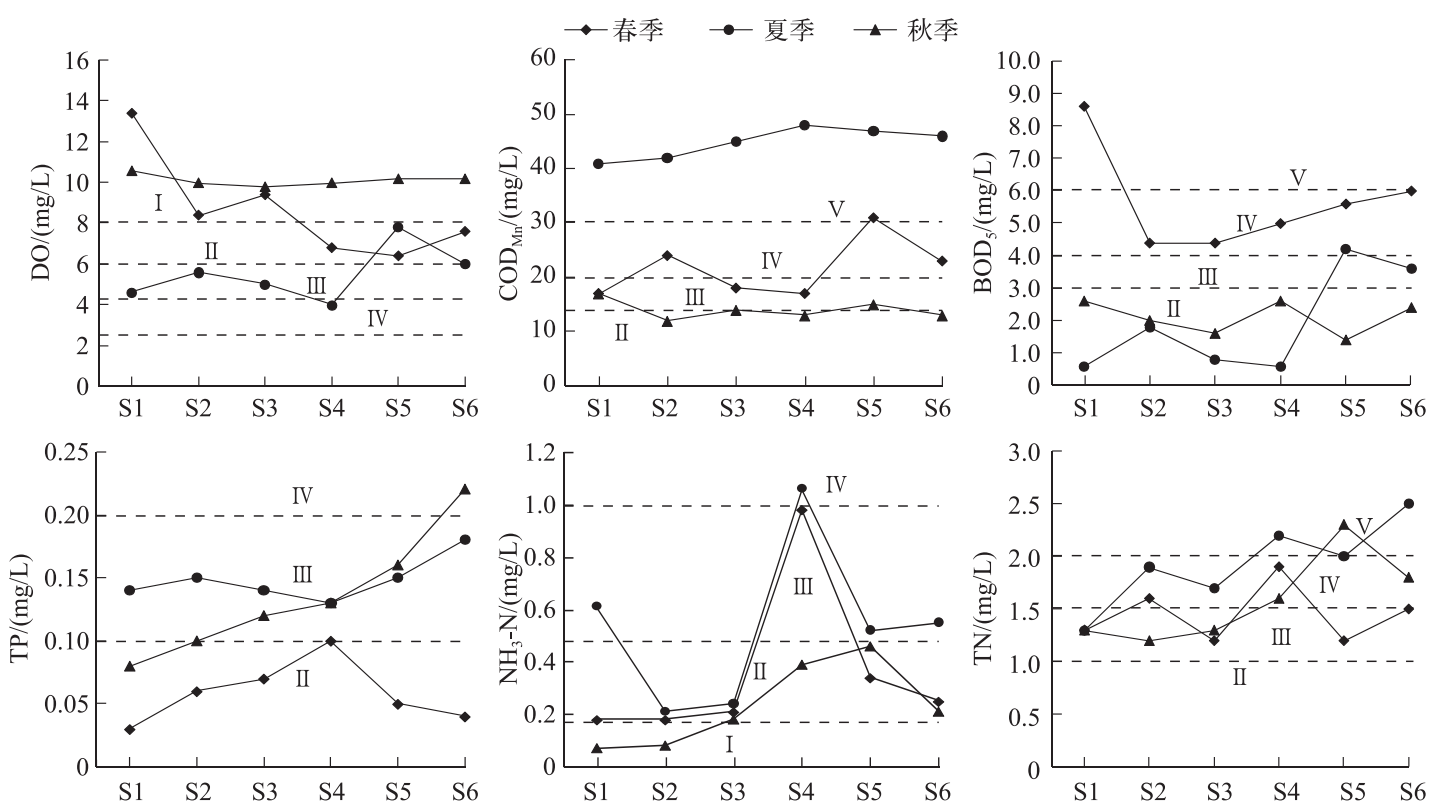

图 3 松花江哈尔滨段水质理化因子污染等级

Fig. 3 The pollution grade in Harbin section of Songhua River based on environmental quality standards for surface water

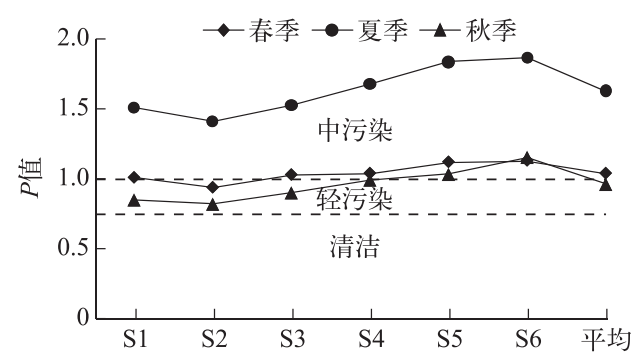

图 4 松花江哈尔滨段水质理化因子 综合污染指数评价

Fig.4 The evaluation statistics of physical and chemical factors in Harbin section of Songhua

River by the integrated pollution index
2.2.2 水质理化因子综合污染指数评价 根据各样点水 质理化数据和综合污染指数的污染等级评价标准评价松 花江哈尔滨段全年水质情况. 结果表明, 春季 $P$ 值在 0.94 1.13 之间, 平均为 1.04 , 除 S2 样点为轻污染外, 其 他样点均为中污染; 夏季 $P$ 值在 $1.41 \sim 1.87$ 之间, 平均为 1.63 , 各样点全部为中污染, 秋季 $P$ 值为 $0.82 \sim 1.15$, 平均 为 0.96 , 除 $\mathrm{S} 5$ 和 $\mathrm{S} 6$ 样点为中污染外, 其余各样点均为轻 污染; 全年 $P$ 值在 $1.06 \sim 1.38$ 之间, 平均为 1.21 , 即水体 为中污染. 从各样点 $P$ 值来看, 3 个季节各样点污染程度 均为 $\mathrm{S} 6>\mathrm{S} 5>\mathrm{S} 4>\mathrm{S} 3>\mathrm{S} 1>\mathrm{S} 2$, 总体为上游水质优于下游. 各季节污染程度排序为夏季 $>$ 春季 $>$ 秋季 ( 图 4).

\section{3 讨论}

\section{1 浮游动物群落结构特征对比分析}

本研究与 2011 年数据相比较 (表 2), 原生动物种类数量相同, 但丰度和生物量分别下降 10 倍, 轮虫种 类数量下降 $1 / 3$, 丰度相差不大, 但生物量较 2011 年下降 15 倍, 枝角类和桡足类现存量差异不大. 3 个年份 各类浮游动物数量占总数的比例结构较类似, 但现存量差异较大, 有研究表明, 温度是影响浮游动物种类和 数量的主要因素 ${ }^{[18]}$, 松花江地处北温带季风气候区, 大陆性气候特点非常明显, 冬季寒冷漫长, 夏季炎热多 雨, 春季干燥多风, 秋季很短, 年内温差较大, 多年平均气温为 $3 \sim 5^{\circ} \mathrm{C}$. 对于浮游动物来说, 夏、秋季水温相对 较高, 食物来源相对充足, 其繁殖较快, 种群数量迅速增长, 而冬季平均水温仅为 $0.5^{\circ} \mathrm{C}$, 浮游动物现存量下 降明显, 即我国北方冬季与其他各季节相比较, 浮游动物种类和数量相差较大. 而在热带水体中 ${ }^{[19]}$, 由于水 温这一关键环境因子的季节变化幅度相对较小, 且全年维持较高水平, 因此其浮游动物群落的种类组成、丰 度和生物量较为稳定. 
表 2 松花江哈尔滨段不同年份浮游动物种类及现存量 *

Tab.2 Zooplankton species and standing crop in Harbin section of Songhua River in different years

\begin{tabular}{|c|c|c|c|c|c|c|c|c|c|c|c|c|}
\hline \multirow[b]{2}{*}{ 年份 } & \multicolumn{3}{|c|}{ 原生动物 } & \multicolumn{3}{|c|}{ 轮虫 } & \multicolumn{3}{|c|}{ 枝角类 } & \multicolumn{3}{|c|}{ 桡足类 } \\
\hline & 种类 & $\begin{array}{c}\text { 丰度/ } \\
\text { (ind./L) }\end{array}$ & $\begin{array}{l}\text { 生物量/ } \\
(\mathrm{mg} / \mathrm{L})\end{array}$ & 种类 & $\begin{array}{c}\text { 丰度/ } \\
\text { (ind./L) }\end{array}$ & $\begin{array}{l}\text { 生物量/ } \\
\text { ( } \mathrm{mg} / \mathrm{L})\end{array}$ & 种类 & $\begin{array}{c}\text { 丰度/ } \\
\text { (ind./L) }\end{array}$ & $\begin{array}{l}\text { 生物量/ } \\
\text { ( mg/L) }\end{array}$ & 种类 & $\begin{array}{c}\text { 丰度/ } \\
\text { (ind./L) }\end{array}$ & $\begin{array}{l}\text { 生物量/ } \\
(\mathrm{mg} / \mathrm{L})\end{array}$ \\
\hline 2011 年 & 9 & 4047.0 & 0.0351 & 41 & 1746.3 & 0.0768 & 2 & 213.0 & 1.0830 & 1 & 97.7 & 0.4740 \\
\hline 2012 年 & 9 & 381.0 & 0.0030 & 27 & 867.4 & 0.0050 & 2 & 36.5 & 0.0650 & 2 & 83.3 & 0.0360 \\
\hline 2013 年 & 2 & 2.5 & 0.0001 & 11 & 27.5 & 0.0649 & 1 & 0.5 & 0.1000 & 1 & 0.5 & 0.0150 \\
\hline
\end{tabular}

* 2011 年 ${ }^{[20]}$ 、2012 年 (本研究) 分别为春季、夏季和秋季数据, 2013 年为冬季数据 ${ }^{[21]}$.

与同一江段其他水生生物相比较, 本研究中浮游动物丰度和生物量季节变化都是秋季高于夏季和春 季, 与浮游植物丰度和生物量季节变化基本一致 ${ }^{[20]}$, 但由于松花江流速较快, 浮游动物和浮游植物的丰度和 生物量相对较低, 底栖动物丰度是春季高于秋季和夏季 ${ }^{[22]}$, 生物量季节变化及水质评价结果与本研究基本 一致.

与北方江河相比较, 本研究与嫩江 ${ }^{[23]}$ 、黑龙汇 ${ }^{[24]}$ 和乌苏里江干流 ${ }^{[25]}$ 浮游动物种类组成特点较为相似, 均以小型类群为主, 其中轮虫种类最多, 原生动物次之, 桡足类和枝角类种类较少, 这与国内很多已知河流 浮游动物群落结构相似 ${ }^{[26-27]}$. 由于轮虫具有独特的孤䧳生殖方式, 能在很短的时间内达到很高的丰度, 并且 很快适应河流中理化环境的改变和水文条件的波动, 因此, 在河流生境中浮游动物通常以轮虫群落为主 ${ }^{[28]}$. 其中, 濑江 ${ }^{[23]}$ 各类浮游动物数量、丰度和生物量分别占总量的比例与本研究极其相似, 各季节丰度变化都是 秋季最高, 春季其次, 夏季最少, 但各季节生物量变化有所不同, 松花江是春季最高, 夏季最低, 嫩江与其相 反. 在优势种和常见种方面, 嫩江 ${ }^{[23]}$ 与松花江都是以轮虫的种类最多, 不同的是嫩江是以龟甲轮虫居多, 同 时桡足类中有中华哲水蚤 (Sinocalanus dorrii)、猛水蚤 (Harpacticoida sp.), 枝角类中有小栉溞 (Daphnia cristata)、僧帽溞 (Daphnia cucullata)、长额象鼻溞 (Bosmina longirostris). 同属北温带的额尔古那河流域各河流虽 然也是以轮虫数量居多, 占总种数的 $34.6 \%$, 但是体型相对较大的枝角类和桡足类占比分别为 $15.4 \%$ 和 $26.9 \%$, 同时其浮游动物的密度和生物量也相对较高 ${ }^{[29]}$. 有研究指出, 鱼类捕食、种类竞争、食物和水文条件 是影响浮游动物群落结构的主要原因. 其中, 由于水文条件的变化, 特别是由降水导致的变化具有很强的随 机性, 导致浮游动物群落季节和年际的随机性 ${ }^{[30]}$. 可见, 即使在北方同一温度带中, 不同河流受到诸多因素 的综合影响, 其浮游动物群落结构也不完全相同.

\section{2 松花江哈尔滨段水质污染源分析}

各样点中, $\mathrm{S} 1$ 样点污染源主要是来自吉林省、齐齐哈尔市和大庆等地的工业排污, 由于经过水体的自净 作用此处污染程度明显下降, 污染程度较轻. S2 样点中水体经过湿地生态系统的进一步净化, 水质污染状况 明显改善. S3 样点原本是哈尔滨市饮用水源地的进水口, 但由于目前水源地已经改为磨盘山水源地, 管理水 平大不如前, 污染主要来自于捕鱼、游钓等人类活动 ${ }^{[20]}$. S4 样点位于市区下游, 同时为阿什河人河口下游, 污染源是多方面的, 主要有沿江河城镇生活排污, 阿什河沿岸炼油厂、塑料加工厂工业废水、废渣排污, 阿什 河中上游农业灌溉中的农药化肥等有毒、有害污水等. S5 样点污染更为复杂, 主要是由肇兰新河污水汇人造 成的, 肇东和大庆乙烯所排放的污水经肇兰新河二道河又汇人呼兰河, 造成呼兰河严重污染. 另外, 呼兰县 的生活污水增多,一些企业至今不建污水处理设施等, 也使得呼兰河污染加剧 ${ }^{\left[{ }^{[11]}\right.}$. S6 样点是综合了市区、郊 区、河口三地污染的所有特点, 因此此处污染最为严重. 综合水质理化指标评价结果来看, 松花江哈尔滨段 上游整体水质要好于下游, 各样点污染程度为 $\mathrm{S} 6>\mathrm{S} 5>\mathrm{S} 4>\mathrm{S} 3>\mathrm{S} 2>\mathrm{S} 1$.

\section{4 参考文献}

[ 1 ] Wang Xiaohui, Wang Tian, Han Boping et al. Species composition and quantitative dynamics of rotifers in a pumped storage, eutrophic reservoir in South China. J Lake Sci, 2009, 21(1) : 101-109. DOI: 10.18307/2009.0113. [王晓辉, 望 甜, 韩博平. 南亚热带富营养化抽水型水库轮虫的组成与动态. 湖泊科学, 2009, 21(1) : 101-109.] 
[ 2 ] Chen FZ, Xie P. The effects of fresh and decomposed Microcystis aeruginosa on cladocerans from a subtropic Chinese lake. Journal of Freshwater Ecology, 2003, 18: 97-104.

[ 3 ] Lin QQ, Duan SS, Hu R et al. Zooplankton distribution in tropical reservoirs, South China. Internat Rev Hydrobiol, 2003, $\mathbf{8 8}(6)$ : 602-613.

[ 4 ] Guevara G, Lozano P, Reinoso G et al. Horizontal and seasonal patterns of tropical zooplankton from the eutrophic Prado Reservoir( Colombia). Limnologica, 2009, 39(2) : 128-139.

[ 5 ] Guo Kai, Zhao Wen, Yin Shouren et al. Relationship between eutrophication status of the water body and rotifer community structure in Guanting Reservoir, Beijing. J Lake Sci, 2010, 22(2) : 256-264. DOI: 10.18307/2010.0216. [ 郭凯, 赵文, 殷守仁等. 北京官厅水库轮虫群落结构与水体富营养化状况. 湖泊科学, 2010, 22(2): 256-264.]

[6 ] Meng Boyang, He Junguo, Wang Peng. Research on spatial and temporal variation of water environmental quality of Songhua River using fuzzy comprehensive assessment method. Journal of Harbin University of Commerce (Natural Sciences Edition ), 2013, 29 (5) : 540-543. [孟伯阳, 赫俊国, 王鹏. 松花江哈尔滨段水环境质量时空变化研究. 哈尔滨商业大 学学报: 自然科学版, 2013, 29(5): 540-543.]

[ 7 ] Fan Qingxin, Yang Xianxing, Qiu Wei. Study on water environmental quality in Harbin section of the Songhua River. China Environmental Science, 2014, 34(9): 2292-2298. [樊庆锌, 杨先兴, 邱微. 松花江哈尔滨段城市水环境质量评 价. 中国环境科学, 2014, 34(9): 2292-2298.]

[ 8 ] Gong Kaiyue. Study on the release law and pollution features of heavy metals in the sediments of Harbin section of Songhua River[Dissertation]. Harbin: Harbin Institute of Technology, 2014. [宫凯悦. 松花江哈尔滨段河流底泥重金属污染及 内源释放规律研究 [学位论文]. 哈尔滨: 哈尔滨工业大学, 2014.]

[ 9 ] Li Jingwen. A research on sediment nutrients release regulations and digital simulation of Songhua River in Harbin region [Dissertation]. Harbin: Harbin Institute of Technology, 2012. [李静文. 松花江哈尔滨段底泥中营养盐释放规律与数 字模拟 [学位论文]. 哈尔滨: 哈尔滨工业大学, 2012.]

[10] Sun Yangyang, Wang Yi, Li Jingwen et al. Characteristics of adsorption of ammonia nitrogen and phosphate by sediments in the Songhua River. Proceedings of conference on environmental pollution and public health ( CEPPH 2012), 2012. [孙 洋阳, 王神, 李静文等. 松花江哈尔滨段河道底泥对氨氮和磷的吸附特性研究. 环境污染与大众健康学术会 议, 2012.]

[11] Subcommittee10 on Fisheries Resource of National Technical Committee 156 on Aquaculture of Standardization Administration of China ed. Specifications for freshwater plankton surveys. Beijing: China Agriculture Press, 2010. [ 全国水产标准 化技术委员会渔业资源分技术委员会. 淡水浮游生物调查技术规范. 北京: 中国农业出版社, 2010.]

[12] Jin Xiangcan, Tu Qingying eds. Specifications for lake eutrophication survey: 2nd Edition. Beijing: China Environmental Science Press, 1990: 301-302. [金相灿, 屠清瑛. 湖泊富营养化调查规范: 第二版. 北京: 中国环境科学出版社, 1990: 301-302.]

[13] Ortells R, Gomez A, Serra M. Coexistence of cryptic rotifer species: Ecological and genetic characterization of Brachionus plicatilis. Freshwater Biology, 2003, 48: 2194-2202.

[14] Wang Fengjuan, Hu Ziquan, Tang Jie et al. Evaluation of water quality and the type of nourishment in the eastern zone of Lake Chaohu by means of zooplankton. Ecological Science, 2006, 25(6): 550-553. [王凤娟, 胡子全, 汤洁等. 用浮游 动物评价巢湖东湖区的水质和营养类型. 生态科学, 2006, 25(6): 550-553.]

[15] Shen Yunfen, Zhang Zongshe, Gong Xunju et al eds. New micro biological monitoring technology. Beijing: China Architecture \& Building Press, 1990. [ 沈蕴芬, 章宗涉, 龚循矩等. 微型生物监测新技术. 北京: 中国建筑工业出版 社, 1990.]

[16] Tong Yan, Ma Mingrui, Lin Qing et al. Dynamics of spatial and temporal distribution of phytoplankton and related affecting factors in the Dishui Lake. Resources and Environment in the Yangtze Basin, 2012, 21(12): 1499-1506. [ 童琰, 马明睿, 林青等. 滴水湖浮游植物时空分布动态及其影响因子. 长江流域资源与环境, 2012, 21(12): 1499-1506.]

[17] Sun Tao, Zhang Miaoxian, Li Miaomiao et al. River water quality evaluation based on correspondence analysis and comprehensive pollution index method. Environmental Science \& Technology, 2014, 37(4): 185-190. [孙涛, 张妙仙, 李苗苗 等. 基于对应分析法和综合污染指数法的水质评价. 环境科学与技术, 2014, 37(4) : 185-190.]

[18] Tao Zhencheng, Zhang Wuchang, Sun Song. The wave-specific influence of visible and ultraviolet light on zooplankton behaviour. Marine Sciences, 2004, 28(9) : 56-61. [陶振铖, 张武昌, 孙松. 可见光和紫外线对浮游动物行为的影响. 
海洋科学, 2004, 28(9) : 56-61.]

[19] Jr Lewis WM. Zooplankton community analysis studies on a tropical system. New York: Spring Verlag, 1979.

[20] Li Xiaoyu, Yu Hongxian, Ma Chengxue. Structure of phytoplankton community based on canonical correspondence analysis and biodiversity analysis in Harbin Section of Songhua River. Journal of Northeast Forestry University, 2013, 41 (10): 103-107. [李晓钰, 于洪贤, 马成学. 松花江哈尔滨段浮游植物群落典范对应分析及多样性分析. 东北林业大学学 报, 2013, 41(10): 103-107.]

[21] Li Zhe, Huo Tangbin, Tang Fujiang et al. The relationship between community structure of plankton and environmental factors in ice-covered water in Harbin Section of Songhua River. Chinese Journal of Fisheries, 2014, 27(6) : 44-50. [李 吉, 霍堂斌, 唐富江等. 松花江哈尔滨段冰下浮游生物群落结构与环境因子的相关分析. 水产学杂志, 2014,27 (6) : 44-50.]

[22] Huo Tangbin, Liu Manhong, Jiang Zuofa et al. Macrobenthos community structure of macrobenthos and bioassessment of water quality in main stream of Songhua River. Chinese Journal of Applied Ecology, 2012, 23(1): 247-254. [霍堂斌, 刘 曼红, 姜作发等. 松花江干流大型底栖动物群落结构与水质生物评价. 应用生态学报, 2012, 23(1): 247-254.]

[23] Huo Tangbin. The study on aquatic biodiversity and ecosystem health assessment in the downstream of Nenjiang River[Dissertation]. Harbin: Northeast Forestry University, 2013. [霍堂斌. 嫩江下游水生生物多样性及生态系统健康评价 [学 位论文]. 哈尔滨: 东北林业大学, 2013.]

[24] Jiang Zuofa, Tang Fujiang, Dong Chongzhi et al. Population structure of zooplankton in Heilongjiang River System. Journal of Northeast Forestry University, 2006, 34(4) : 64-66. [姜作发, 唐富江, 董崇智等. 黑龙江水系主要江河浮游动物 种群结构特征. 东北林业大学学报, 2006, 34(4): 64-66.]

[25] Su Jie, Jiang Zuofa, Li Chitao et al. Zooplankton composition in Heilongjiang River. Chinese Journal of Fisheries, 2005, 18(1) : 18-23. [苏洁, 姜作发, 李池陶等. 黑龙江浮游动物群落结构特征. 水产学杂志, 2005, 18(1): 18-23. ]

[26] Hong Song, Chen Jingsheng. Structure characteristics of aquatic community from the main rivers in China. Acta Hydrobiologica Sinica, 2002, 26(3) : 295-305. [洪松, 陈静生. 中国河流水生生物群落结构特征探讨. 水生生物学报, $2002,26(3): 295-305$.]

[27] Wu Li, Feng Weisong, Chen Xiaojuan et al. Community structure characteristics of zooplankton in Yili region of Xinjiang in summer. Chinese Journal of Applied Ecology, 2008, 19(1): 163-172. [吴利, 冯伟松, 陈小娟等. 新疆伊犁地区夏 季浮游动物群落结构特征. 应用生态学报, 2008, 19(1): 163-172.]

[28] Holst H, Zimmermann H, Kausch $\mathrm{H}$ et al. Temporal and spatial dynamics of planktonic rotifers in the estuary dining spring. Estuarine, Coastal and Shelf Science, 1998, 47: 261-273.

[29] Jiang Ying, Yao Jinxian, Pang Ke et al. Community structure characteristics of zooplankton in Argun Drainage Area in autumn. Acta Scientiarum Naturalium Universitatis Pekinensis, 2010, 46(6) : 870-876. [姜英, 姚锦仙, 庞科等. 额尔古 纳河流域秋季浮游动物群落结构特征. 北京大学学报: 自然科学版, 2010, 46(6):870-876.]

[30] Xi Lihong, Li Huiming, Lin Qiuqi et al. Structure and seasonality variations of zooplankton community in the pelagic zone of tropical Dashahe Reservoir, Guangdong, South China. J Lake Sci, 2015, 27 (6) : 1049-1058. DOI: 10.18307/2015. 0609. [习丽红, 李慧明, 林秋奇等. 热带富营养水库敞水区浮游动物群落结构与季节变化: 以广东大沙河水库为 例. 湖泊科学, 2015, 27(6): 1049-1058.]

[31] Zhang Jing, Yu Hongxian. Study on zoobenthos community structure and water quality assessment in Songhua River along Harbin city. Chinese Journal of Fisheries, 2009, 22(2) : 40-45. [张静, 于洪贤. 松花江哈尔滨段春季底栖动物群落 结构研究及水质评价. 水产学杂志, 2009, 22(2): 40-45.] 